\title{
A escolha feminina na área das profissões tecnológicas: impactos na subjetividade
}

Maria Sara de Lima Dias msaradldias@gmail.com Universidade Tecnológica Federal do Paraná (UTFPR), Curitiba, Paraná, Brasil.

\section{RESUMO}

\begin{abstract}
As mudanças sociais no trabalho representam para as mulheres mobilização de ações configurando novos modos de produção de subjetividades. Neste artigo se pretendeu abordar à escolha feminina na área das profissões tecnológicas, analisadas através de um recorte de uma pesquisa maior na qual se buscou identificar qual o perfil das(os) egressas(os) da UTFPR na área tecnológica (engenharias). Como procedimentos foi encaminhado um questionário on-line para as(os) egressas(os) das engenharias de 2005 a 2015. Os resultados demonstram 23\% de mulheres nas engenharias, estas buscam melhores maiores salários e condições de vida através de uma maior qualificação profissional. A inserção na engenharia está associada ao combate de diferentes formar de preconceitos e repercutem em um tipo de sofrimento ético e político no trabalho. Concluise que as instituições formadoras devem impulsionar discussões sobre gênero para o enfrentamento de preconceitos no trabalho ao privilegiar o direito à diversidade no trabalho.
\end{abstract}

PALAVRAS-CHAVE: Políticas educacionais. Qualificação. Escolha profissional. 


\section{INTRODUÇÃO}

As mudanças históricas e sociais associadas ao mundo do trabalho e das profissões nascem cheias de promessas de progresso, de equidade e de justiça social. Em relação à promoção de igualdade a Organização das Nações Unidas (ONU) reconhece que o Brasil teve avanços.

Conforme documento oficial do portal do Planalto, baseado na Pesquisa Média de empregos (Planalto, 2012) entre 2003 e 2011, o rendimento médio das mulheres cresceu $24,9 \%$, variação superior à observada entre os homens. Tratase de um referência ao IBGE em sua pesquisa sobre a Pesquisa Mensal de Emprego (PME), considerando o rendimento médio recebido pelo trabalhador, assim o salário das mulheres subiu, porém ainda não se igualou, é preciso deixar claro ainda que na mesma pesquisa do IBGE, verificou-se que nos diversos grupamentos de atividade econômica, a graduação superior não aproximou os rendimentos recebidos por homens e mulheres, pelo contrário, acentuou-se a diferença. (IBGE; 2014).

Embora a questão da mulher no mercado de trabalho seja uma característica das mudanças sociais envolvidas na procura por profissões melhor remuneradas, o processo de aproximação da mulher para as profissões tecnológicas é historicamente forjado por lutas por direitos sociais e formulação de políticas educativas. Segundo Scott (2006, p. 3) "gênero" era um termo proposto por aquelas que defendiam que a pesquisa sobre mulheres transformaria fundamentalmente os paradigmas no seio de cada disciplina". Porém para a autora "a maneira como esta nova história iria simultaneamente incluir e apresentar a experiência das mulheres dependeria da maneira como o gênero poderia ser desenvolvido como uma categoria de análise" (Scott, 2006, p. 4). Neste artigo se observa o impacto histórico da divisão sexual do trabalho pelo capitalismo; utilizando o termo mulher no mercado de trabalho e o caráter da integração específica de grupos de engenheiras aos modos de produção e reprodução deste mercado de trabalho,não sendo intenção da autora aprofundar o debate sobre o conceito de gênero e sim reconhecer as mudanças contemporâneas nos modos de produção do trabalho.

Segundo Hirata e Kergoat (2003, p. 114) "[...] falar de divisão sexual do trabalho e de relações sociais de sexo não remete unicamente a uma abordagem macrossociológica [...] mas integra simultaneamente uma reflexão sobre a subjetividade." A diversidade e a contradição presente nas escolhas profissionais está presente nas discussões sobre emprego, desemprego e exclusão.

Contudo ao se estabelecer um paralelo entre a formação de homens e mulheres na área tecnológica, considerando aqui as engenharias, permanece o trabalho uma categoria central para a vida em sociedade, no qual as mulheres ainda não tem um estatuto equivalente ao dos homens. No reconhecimento de que os sistemas econômicos alteram os modos de produção e reprodução do capital e de que as questões de formação para o trabalho perpassam os sistemas de inclusão e exclusão de homens e mulheres, a procura por profissões melhor remuneradas é uma constante, motivada por uma imensa valorização midiática (Guia, 2017). Não é somente a questão de que o trabalho nas engenharias seja claramente supervalorizado na mídia, mas também do valor moral e social que este representa dentro da sociedade da qual fazemos parte. 
As discussões acerca da igualdade entre homens e mulheres no mercado de trabalho muitas vezes são deslegitimadas por críticas que tomam o papel recente da mulher em determinadas áreas do saber, portanto é fundamental pesquisar o perfil da mulher no mercado de trabalho. Pesquisa do Instituto Ethos (2016) com as quinhentas maiores empresas do Brasil, aponta que grande parte das organizações tampouco desenvolve alguma política visando a promoção da igualdade de oportunidades entre homens e mulheres. E expressivas parcelas dos principais gestores percebem como adequada a participação de mulheres e negros em praticamente todos os níveis hierárquicos. Portanto o Brasil ainda se "situa entre as nações mais desenvolvidas economicamente, continua apresentando desigualdades sociais de caráter estrutural, que se refletem no mundo do trabalho" (Instituto Ethos, 2016, p. 5).

$\mathrm{Na}$ mesma pesquisa, no entanto, se apresenta que entre as quinhentas maiores empresas existem aquelas que sinalizam a possibilidade de adoção de medidas de conciliação entre trabalho, família e vida pessoal; a manutenção de canais para receber queixas dos funcionários em relação a problemas como assédio moral e preconceitos. A que se considerar portanto algum avanço no perfil das empresas brasileiras e no mercado de trabalho que repercutem em uma maior participação feminina em diferentes postos de trabalho. Dentre as modificações sociais relativas a presença de mulheres em profissões tecnológicas, considerando especificamente neste artigo como as engenhais, estas se relacionam direta e indiretamente com uma maior presença das mulheres nas universidades. Nas últimas décadas, a presença das mulheres na universidade tem-se mostrado uma das mais significativas alterações no público atendido e na demanda por novos perfis profissionais, com desdobramentos nos mais diferentes segmentos da sociedade conforme Kühlkamp, Sandrini, Teixeira e Mattos (2015).

Tais processos de promoção de igualdade podem mascarar a realidade do mundo trabalho e das profissões, uma vez que no ambiente de trabalho a remuneração média das mulheres ainda correspondia a $72,3 \%$ da masculina em 2011, na mesma função conforme IBGE (2014).

Embora o termo trabalho seja utilizado, muitas vezes de maneira reducionista, somente para descrever as atividades remuneradas e executadas dentro das organizações, pode-se observar que a atividade de qualquer profissional mobiliza tanto energias físicas como mentais, além de emoções que são frequentemente associadas ao gênero. Deste modo a mobilização de ações institucionalizadas ou não vão configurando novos modos de produção de subjetividades. Destaca-se que a subjetividade é um construto histórico que se desenvolve juntamente com o capitalismo, quando há uma valorização da vida privada do indivíduo. Sobrevém daqui a concepção de sujeito vinculada à noção de privacidade, e de individualidade, permitindo o sentimento de eu (Bock, 2009).

Ao buscar superar os entraves econômicos, sociais e históricos do mercado de trabalho as mulheres têm buscado cada vez mais as profissões tecnológicas especialmente as engenharias. Isto se relaciona com vários fatores, entre estes as políticas educativas que são frequentemente mobilizadas por acordos internacionais. Para Teixeira (2010) a preocupação com a educação de mulheres aparece com maior intensidade na década de 90. Por exemplo, no Marco de Ação 
de Dakar (2000) são metas eliminar as disparidades de gênero (até 2005) e alcançar a igualdade de gênero (até 2015) na educação, buscando a educação de cada cidadão e para cada sociedade. A educação é vista como um dos direitos fundamentais das pessoas.

Diversas pesquisas apontam para associações significativas entre o trabalho e o gênero, porém existem poucos estudos empíricos na área baseados principalmente nas(os) egressas(os) do ensino superior, conforme Kühlkampe Teixeira (2013). Entre os modelos descritos dos processos de inovação sócia histórica aplicável ao mundo do trabalho, podemos destacar os seguintes: a separação precisa do lugar de trabalho (a fábrica) do tempo de trabalho (jornada laboral) com respeito ao espaço-tempo privado familiar; a mercantilização do trabalho convertido em um valor de troca. Essa situação inspira e legitima a manutenção da estrutura e do modelo e dinâmica de trabalho, de acordo com as circunstâncias históricas e sociais(CANTERA et al.2009).

Neste artigo se pretendeu abordar a presença feminina na área das profissões tecnológicas considerando especificamente as escolhas das engenharias: mecânica, elétrica, de automação e civil, apontando para possíveis impactos nos modos de produção de subjetividades. Tais dados foram analisadas através de um recorte de uma pesquisa maior que buscou identificar qual o perfil dos egressos da UTFPR na área tecnológica (engenharias).

\section{METODOLOGIA}

Com base nos fundamentos epistemológicos, teóricos e metodológicos da psicologia comunitária, foi realizada uma pesquisa exploratória com os egressos dos cursos superiores da Universidade Tecnológica Federal do Paraná (UTFPR) na área tecnológica. A psicologia comunitária adota o paradigma da construção e da transformação crítica em cada uma das cinco dimensões que propõe para a psicologia, como uma forma de rompimento com modelos hegemônicos de teorias psicológicas dominantes. A psicologia social comunitária apresenta, na dimensão ontológica, a categoria de atores sociais, posto que o sujeito do conhecimento qualquer que seja a sua procedência é também o sujeito que critica, atua e reflete sobre a própria realidade que o constitui, a partir de seus discursos e de suas ações. Na dimensão epistemológica esta se refere à própria produção do conhecimento como construção social e portanto relativa, já que é produzida historicamente. $\mathrm{Na}$ dimensão metodológica a construção do conhecimento não pode ser dada à partir da distância entre sujeito e objeto, talvez o mais interessante dos fundamentos metodológicos propostos segundo Montero $(2004$, p. 98) "é a necessidade de gerar métodos que transformem ao mesmo tempo que mudam as comunidades". Ou seja métodos capazes de mudar conforme se mudam os problemas que se estuda, de tal maneira que gerem construções críticas e reflexivas de caráter coletivo sobre a realidade estudada.

A pesquisa foi classificada como um estudo de caso, segundo Montero (2004) por tratar especificamente de uma universidade, com caráter tecnológica, única universidade pública e gratuita no país e neste estudo por seu enfoque 
engenharias. A população pesquisada foi alcançada a partir do sistema corporativo a UTFPR, que em seu banco de dados que contém o registro acadêmico dos alunos de todos os ofertados pela instituição. $O$ recorte da pesquisa selecionou egressos de todos os cursos engenharias nos últimos dez anos, período em que a instituição se tornou uma IES, Instituição de Ensino Superior. A amostra compreendeu a totalidade de formados de todos os cursos de engenharias, 2.680 pessoas que receberam a pesquisa, sendo 2.300 e-mails validos. 0 número de 247 respondentes é uma amostra significativa, dos cursos das engenharias. $O$ questionário seguiu questões que permitem investigar profundamente o perfil do egresso mas neste artigo, é preciso enfatizar, tratase de um recorte da pesquisa, cuja proposta é a analisar a presença das mulheres nas áreas de profissões tecnológicas (engenharias) e descrever como se comporta esta força de trabalho atualmente, demonstrando impactos na subjetividade sem ter qualquer intuito de esgotar o tema ou de analisar diferenças mais específicas que se situam entre as ocupações que cada curso pode comportar e sim buscando um panorama mais geral das mulheres nas engenharias.

\section{DESENVOLVIMENTO (RESULTADOS E DISCUSSÕES)}

Obteve-se um total de 247 respostas dos questionários validados o que representa $13 \%$ dos alunos pesquisados no período em questão neste estudo, ou seja nos últimos dez anos. As características desta população conformam uma presença de $23 \%$ de mulheres nas engenharias formadas, sendo $76,9 \%$ homens formados. A participação de um número muito menor de mulheres na área tecnológica (engenharias) confirma múltiplas particularidades da história da educação superior, da econômica e da sociedade, como um fenômeno que aponta a formação superior como um diferenciador relacionado ao gênero. Conforme o gráfico (1):

Gráfico (1) Distribuição das(os) engenheiras(os) formados por sexo.

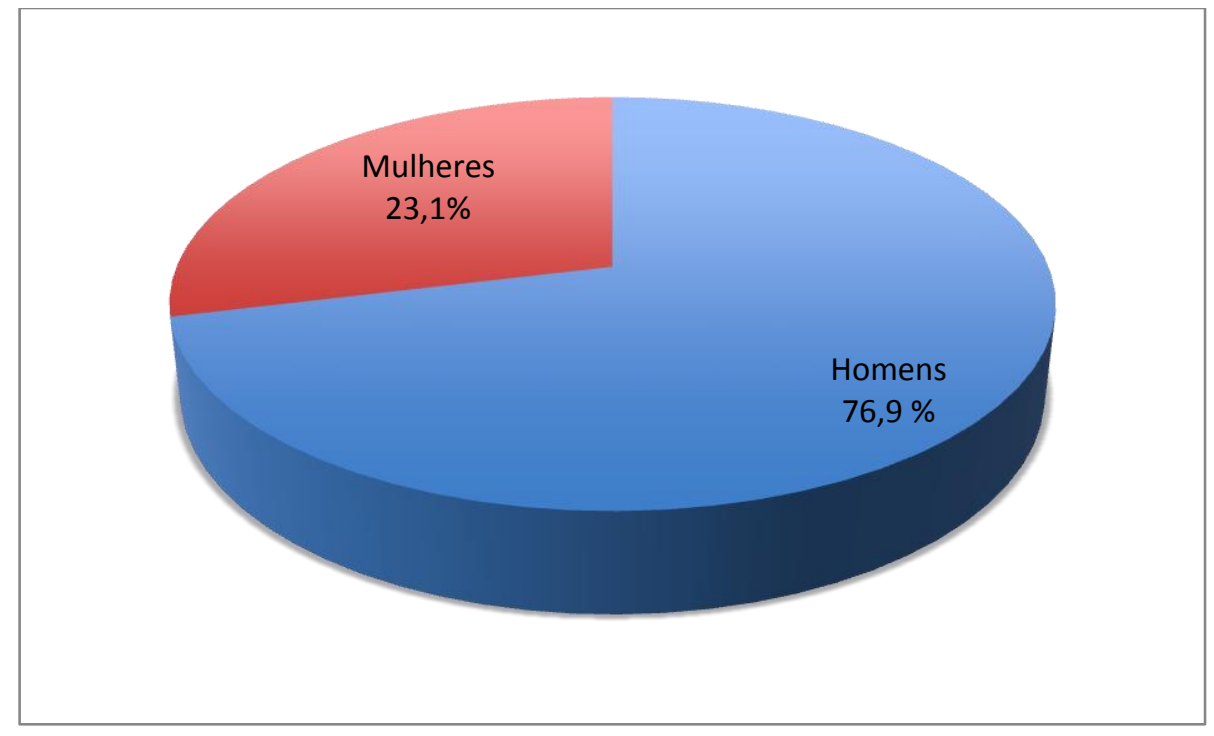

Fonte: Dados da pesquisa da autora.

Os dados da pesquisa demonstram as barreiras impostas à inserção das mulheres na ciência (exatas/hard) e, às facilidades encontradas pelos homens 
para essa mesma inserção. Ainda que a história da UTFPR tenha se pautado sobre bases androcêntricas e excludentes de pelo menos metade da população, os avanços surgem (Saraiva, 2005) como demonstrado neste estudo por uma maior titulação das mulheres neste campo que é historicamente construído como masculino. Entre as várias razões para explicar a pequena presença das mulheres na engenharia, situam-se algumas para Lombardi (2016, p. 4):

\begin{abstract}
Algumas se reportam a limitações impostas pela profissão e sua origem militar outras as condições de trabalho adversas encontradas pelos profissionais em algumas especialidades, o comando de equipes masculinas; outras localizam o problema numa incompatibilidade entre a engenharia e uma dada concepção de feminino, avessa às matemáticas, à racionalidade e à objetividade, não predispostas à competição, imagens de gênero atribuídas `à engenharia e ao masculino.
\end{abstract}

Segundo a autora as pesquisas remetem a um processo chamado de feminilização entendido como o aumento do número de mulheres nas engenharias que no entanto é mais lento do que em outras profissões.

Assim não se pode falar de um único elemento diferenciador da educação superior na área tecnológica uma vez que a pouca presença das mulheres na área das engenharia se vincula a vários fatores, conforme a pesquisa de estado da arte de Lombardi (2016) buscando direções e reflexões sobre porque são poucas as mulheres nas engenharias, classifica estas pesquisas nos seguintes eixos temáticos de investigação: engenharia e gênero: formação e docência; engenharia e gênero: trabalho e mercado de trabalho; pioneiras nas engenharias e engenharia e gênero: pesquisa, produção científica e tecnológica.

Aspectos históricos das pesquisas sobre engenharia e gênero demonstram um aumento do interesse na temática da presença feminina em profissões tradicionalmente masculinas (Lombardi, 2016). Explicações sobre as carreiras e o aumento da participação das mulheres no mercado de trabalho das engenharias remontam à considerações do início da formação. Historicamente considerando que as escolas de engenharia nasceram em berço militar, somente homens frequentavam a Escola Politécnica no Rio de Janeiro. As mulheres iniciam uma formação na área das engenharias somente no início do século XX. A engenharia se estabelece como profissão somente em 1930 acompanhando um processo de industrialização do pais ainda incipiente no qual as mulheres vão buscando novos espaços de profissionalização. Para Lombardi (2016) a formação universitária está em pauta em muitas pesquisas, que selecionam motivos para explicitar a presença reduzida das mulheres nas engenharia, por exemplo mencionam processos de socialização de meninos e meninas, nas escolas e nas famílias, que acabam incentivando escolhas profissionais.

Para Dowbor (2003, p. 33)

a inserção da mulher no mundo do trabalho remunerado constitui uma onda de profundas mudanças, alcançada por outra mais poderosa, de desarticulação das formas tradicionais de organização do trabalho, das (poucas) garantias sociais, dos (precários) sistemas de solidariedade social.

Conforme aponta estudo do Departamento Intersindical de Estatística e Estudos Socioeconômicos (Dieese) para a Federação Nacional dos Engenheiros (FNE), em dez anos - entre 2003 e 2013 - o número de engenheiras passou de 
24.554 para 57.022 , um crescimento de $132,2 \%$. Já a inserção masculina nesse período ampliou-se 78,3\%, de acordo com as informações da FNE (2016).

A engenharia no Brasil, apesar de ser uma categoria majoritariamente masculina, na qual os homens representavam $79,2 \%$ do total dos engenheiros empregados em 2009, tem o aumento da participação das mulheres sua participação em 2009, eram 18,7\%; e em 2013, atingiram o patamar de 20,8\%, conforme dados da FNE (2016).

Corroborando os dados da nossa pesquisa com as egressa(os) como se pode observar pelos dados do gráfico a seguir, a partir de 2005, a participação feminina nos cursos de engenharia da UTFPR, embora de forma discreta, cresceu continuamente, aumentando o número de mulheres formadas na área. (Gráfico 2).

Gráfico (2) Distribuição das(os) formadas(os) por ano e por sexo.

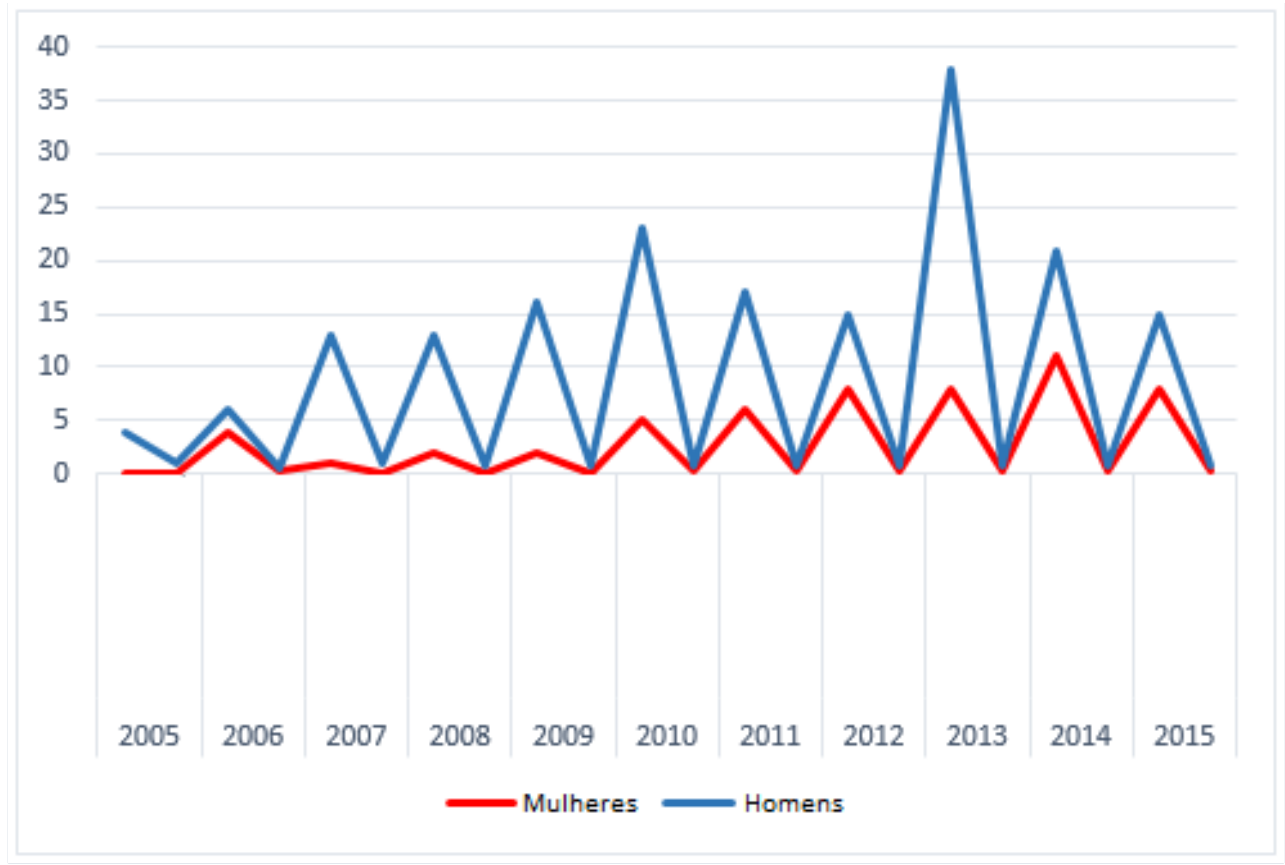

Fonte: Dados da pesquisa da autora.

Quando nos referimos à presença feminina na área das profissões tecnológicas, a dimensão do aumento do número de formadas no curso superior nas engenharias deve ser considerada ainda pequena se comparada com os homens. Neste gráfico o ano de 2013 e 2014 respectivamente apontam para uma maior saída de alunos formados com a perspectiva das carreiras nas engenharias, este dado nos aponta para a hipótese de que a maior saída de graduados nestes períodos pode corresponder ao fator maior entrada de mulheres a partir do Exame Nacional do Ensino Médio (ENEM) e suas repercussões diretas e indiretas na formação da força de trabalho no Brasil.

Historicamente a escolha profissional também é decorrente de movimentos e políticas educacionais que alteram as ofertas e demandas por cursos superiores e que estiveram em curso no Brasil, nos últimos anos. O projeto pedagógico de abrangência nacional nomeado de Enem (Exame Nacional de Ensino Médio) pode 
ser um dos muitos fatores que permitem indicar hipoteticamente o crescente ingresso na mulher na área tecnológica em nosso estudo, o que orienta a necessidade de maiores pesquisas a este respeito para confirmar ou refutar tal hipótese. Para Daune-Richard (2003, p. 65) "o aumento do nível de formação das mulheres ocorre num respeito relativo ao caráter sexuado das carreiras de orientação, e o aumento de atividades das mulheres alimentou sobretudo os setores de empregos já feminizados".

Ainda para Daune-Richard (2003, p. 65) quando se observa a distribuição de homens e mulheres nas carreira de formação técnica, este critério técnico surge como discriminatório:

os homens se encontram muito mais frequentemente que as mulheres nos espaços considerados técnicos, isto é, circunscritos à indústria, onde o trabalho aparece amplamente instrumentado por máquinas. A presença das mulheres é largamente concentrada no terciário, no espaço do relacional.

Quando se observam as expectativas subjetivas de formação na área tecnológica, estas representam tanto para mulheres como para os homens uma vinculação desta qualificação com o aspecto material do trabalho. Quando questionados na pesquisa sobre motivos que influenciaram a escolha profissional o fator remuneração está presente em $45 \%$ dos participantes egressas(os).

O mercado no entanto não é igualitário, a diferenciação do aumento da participação da mulher no orçamento doméstico no Brasil, representa a possibilidade e ao mesmo tempo um aumento do risco ao pensar sobre o futuro profissional e a carreira das mulheres engenheiras. De acordo com Instituto Brasileiro de Geografia e Estatística - IBGE (2014) que elaborou o estudo Estatísticas de Gênero, em 2000, as mulheres chefiavam 24,9\% dos 44,8 milhões de domicílios particulares. Em 2010, 38,7\% dos 57,3 milhões de domicílios registrados já eram comandados por mulheres. Demonstra a desigualdade presente na sociedade brasileira particularmente. Para Daune-Richard (2003, p. 70) "Se o masculino é associado à modernidade da razão, do trabalho, da liberdade e do cidadão, o feminino é ligado à antiga ordem social da família, da dependência e da naturalidade".

Para Lombardi (2016) ainda tratando do ambiente da engenharia, outro motivo para o pequeno número de mulheres na área, afirma que seriam as práticas pedagógicas adotadas nos cursos de engenharias, nas quais as relações entre alunos e professores tendem a reproduzir desigualdades.

Ao olhar o avanço de uma maior participação feminina em diferentes cursos, também deve-se assinalar que este ocorre de forma diferenciada. Conforme o tipo de formação que se está buscando relativa à expectativas das ofertas de postos de trabalho subjetivamente apreendidas pelos atores sociais e que tenham privilegiado nesta percepção de alguma forma os profissionais das engenharias. Se observa no gráfico 3 um aumento na busca das engenharias ao longo do período da pesquisa também de forma diferenciada. 
Gráfico (3) Distribuição da(os) engenheiras(os) por curso e por sexo.

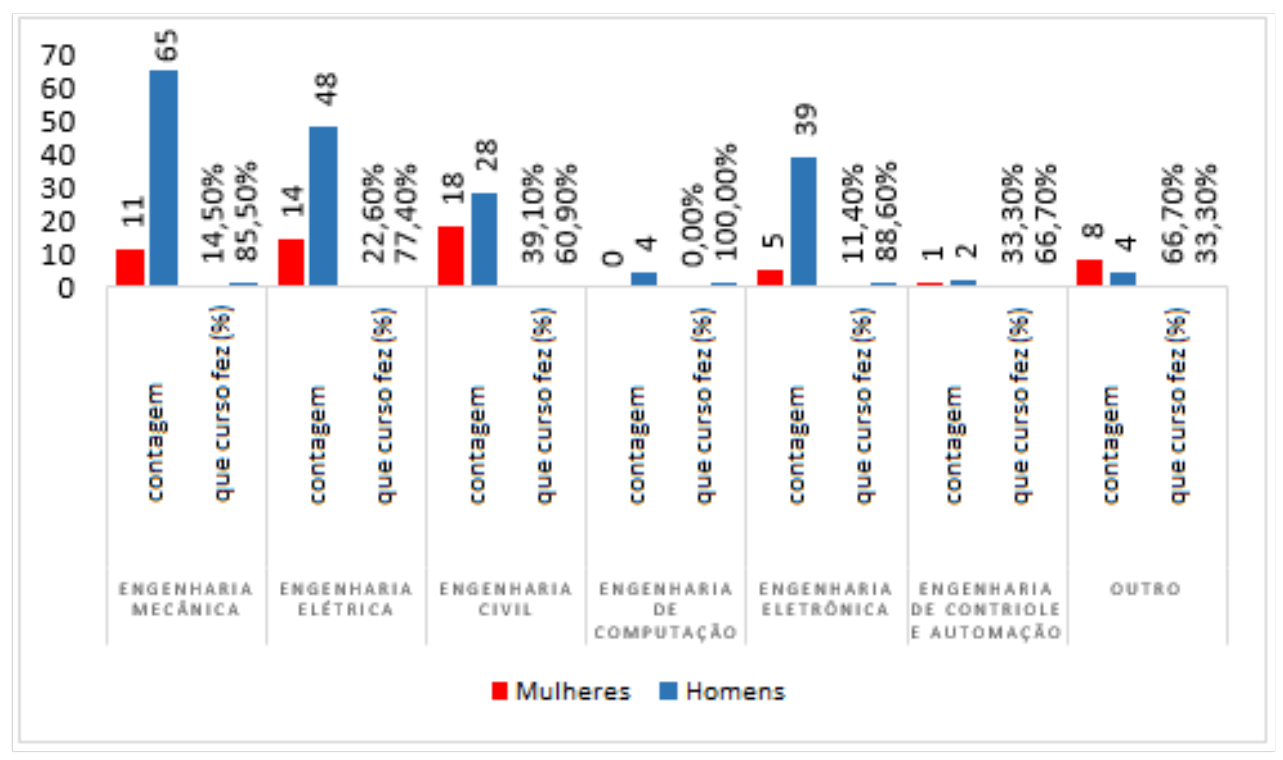

Fonte: Dados da pesquisa da autora.

No gráfico 3 se observam as profissões tecnológicas, aqui analisadas especificamente as engenharias que demonstram uma maior procura das mulheres pela engenharia civil, seguida pela engenharia elétrica e mecânica. No entanto, há que se relativizar os dados da pesquisa, uma vez que se trata de um caso especifico em uma universidade específica. Além do fato de que os cursos de engenharia civil são também os mais antigos na instituição e tem datas diferentes de aberturas e ofertas de vagas. Considerando que só podem ser objeto de interesse das mulheres se existirem ofertas de vagas para as demandas existentes. A engenharia civil é o curso que tem maior número de mulheres formadas nos últimos dez anos na instituição, seguida da engenharia elétrica e da engenharia mecânica embora a engenharia eletrônica e de controle de automação também tenham recebido formadas neste estudo.

Quando questionados os sujeitos especificamente sobre os motivos que influenciaram a escolha da área profissional, descrevem esta escolha como motivada por: afinidade, aptidão nas exatas, mercado de trabalho favorável, vocação, gosto, identificação, remuneração, salário, curiosidade, interesse por máquinas, tecnologia e criação de máquinas. Neste sentido de modo indistinto entre homens e mulheres as possibilidade de ingresso no mercado de trabalho seguida pela dimensão da perspectiva de melhor remuneração são motivos alegados por todos os grupos sociais pesquisados.

No contexto deste artigo cujo objetivo foi apontar para a presença da mulher na área tecnológica os dados referentes à vinculação a uma identidade de engenheira, de mãe e de professora são levantados em diferentes momentos da 
pesquisa distribuídos nas diferentes questões pesquisadas sobre o trabalho da engenheira. Entre tais expectativas subjetivas de escolha do curso, verificou-se intenso interesse das mulheres para a atuação como docente em nível superior. Assim os dados levantados por cruzamento entre as expectativas da escolha e grau formação das egressas demonstram a expansão do conhecimento através das especializações, do mestrado e do doutorado e também legitimam uma maior qualificação da mulher na engenharia. Como nesta narrativa:

“- A possibilidade de continuar estudando, aprendendo e ensinando e descobrindo coisas novas é o que mais me motiva na carreira acadêmica".

Desta forma a valorização subjetiva da acadêmica-científica perpassa o perfil das egressas, demonstrando uma identidade construída e legitimada na universidade, que, porém, não é reduzida a ela. Através da carreira acadêmica se permite a continuidade de uma trajetória identitária da engenheira e da professora que se desenvolve também em função da possibilidade de conciliar a vida profissional e pessoal.

O egresso do sexo masculino não apresenta em seu perfil esta chamada de atenção para a relação entre a vida profissional e pessoal. A egressa em seu discurso vai relacionando suas escolhas, com certos níveis de atividades como cuidar da família. Como exemplo, nesta narrativa:

“- A intenção de obter uma formação de qualidade e gosto pela matemática. No entanto, inicialmente o objetivo era cursar algum curso de engenharia, mas a própria matemática revelou ótimos caminhos para se profissionalizar (mestrado e doutorado, pensando em ser professora universitária e mãe".

As mulheres demonstram ações e reações sobre a escolha da engenharia que são específicas deste grupo social, que demonstram conforme HIRATA (2003) a consideração à família e as relações domésticas. A imbricação do trabalho profissional e do trabalho doméstico, é específica no grupo de mulheres diferente do grupo de homens, no qual não surgem preocupações tão evidentes com o papel de pai ou de esposo.

Para as mulheres, a área das engenharias se convertem também em novas demandas para as carreiras acadêmicas, conforme pode se observar no gráfico (4) relacionando escolhas de carreira com grau de escolaridade. Conforme Daune-Richard (2003, p. 71) "à construção social do trabalho qualificado repousa fundamentalmente nos processos de diferenciação entre tipos de tarefas e entre os trabalhadores que as executam". No entanto, novas pesquisas podem apontar para os limites e possibilidades destas relações entre papéis sociais e gênero. 
Gráfico (4) Distribuição das engenharias formados por grau de escolaridade.

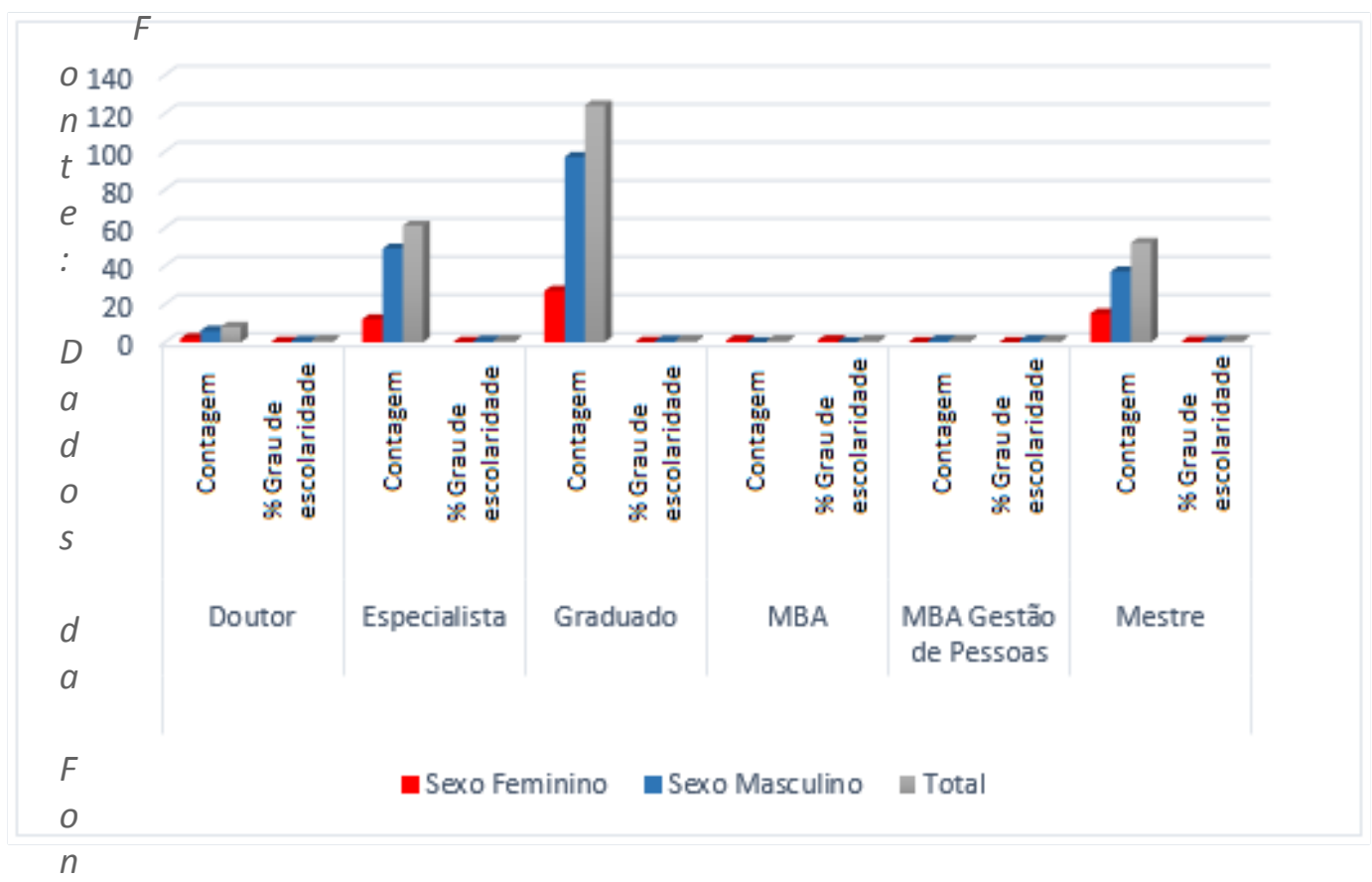

Fonte: Dados da pesquisa da autora.

O gráfico acima apontam esta maior busca por qualificação profissional que nada obstante pode estar relacionada direta ou indiretamente também a uma carreira docente como alternativa. Segundo Lombardi (2016) existe uma correlação importante entre por um lado profissionais altamente qualificadas, ocupando posições de prestígio e relativamente bem remuneradas como engenheiras, arquitetas e outro a imensa maioria de trabalhadoras não qualificadas, ocupando empregos mal remunerados e não valorizados socialmente. Representam neste sentido um movimento de busca por caminhos alternativos. Talvez caminhos em que se possa conciliar papéis impostos socialmente para as mulheres, como a maternidade, o casamento e a família e que repercutem nas profissões de modo significativo. Para Hirata (2003, p. 20)

Enquanto a conciliação entre vida profissional e vida familiar, trabalho assalariado e trabalho doméstico for pertinente exclusivamente para as mulheres, as bases em que se sustenta essa divisão sexual não parecem estar ameaçadas em seus fundamentos.

As engenharias são hoje tidas como áreas que atuam em múltiplas profissões e com maior especificação na gestão de organizações, desenvolvimento de projetos, inovação, software entre muitos outros campos de atuação. Essa multiplicidade de possibilidades faz da formação um processo ao mesmo tempo flexível em se ter outras atuações e por outro lado em ser resposta a mercados que notadamente dão ênfase ao conhecimento abstrato e aplicado. Contudo as pesquisas apontam também para o peso das instituições e dos contextos socioculturais nas modalidades da divisão do trabalho profissional e doméstico. Segundo HIRATA, (2003, p. 122)

Mostram concretamente como a dimensão relativa à sociedade das práticas sociais mais diversas-responsabilidade sobre o cuidado de crianças, 
mulheres fazem da legislação-repercute e modela as divisões sexuadas do trabalho.

O aspecto econômico paralelamente a uma maior expansão da educação superior repercutem nas escolhas profissionais como diferenciadores. Como nesta narrativa sobre o porquê escolheu a área da engenharia: "- Mercado favorável e salário". A inquietude quanto ao mercado de trabalho e a possibilidade de renda geram uma busca de qualificação profissional, mais estratégica e aliada as ofertas e demandas do mundo do trabalho. As engenharias, na percepção das egressas promovem maiores salários e condições de vida, são áreas que permitem maior mobilidade para outras atividades como a gestão e o ensino. As motivações subjetivamente apropriadas na trajetória sócio profissional (Dubar, 1998), confirmam a busca de segurança no mundo do trabalho. Garantias contra os imprevisíveis caminhos que levam ao contínuo desenvolvimento profissional a determinar-se como um projeto de vida e carreira no campo da engenharia.

A combinação de interesses familiares, particulares, públicos e privados na escolha da área tecnológica, resultam também de extrema insegurança vivenciada pela egressa do sistema de ensino, quando da sua entrada no mercado de trabalho. A engenharia está vivenciando um tempo histórico em que o processo de transição ganha contornos diferenciados com o aumento do número de cursos superiores, as estatísticas veiculadas na mídia sobre o desemprego e o alargamento do tempo de permanência na universidade, entre outros fatores(DIAS et al. 2012).

O desenvolvimento da flexibilização e da polivalência do trabalhador, está relacionado com a relação dialética deste com a sociedade. Desta forma todas as mudanças sociais afetam as relações de gênero, representando um conjunto de trabalhos, ocupações e profissões que serão determinantes para o acesso da mulher ao mercado de trabalho, afetando as trajetórias sócio profissionais e as escolhas (Dubar, 1998) de modo diferenciado. Como nestes relatos de uma engenheira civil:

“- Não tenho grandes expectativas, por isso estou migrando para a área acadêmica. “

E de uma engenheira mecânica:

"- Redescoberta. O curso de Engenharia me mostrou qual a linguagem do Engenheiro, como um profissional dessa área deve observar os problemas a fim de solucioná-los da melhor forma possível. Portanto, posso dizer que entrei no curso de Engenharia como estudante e me redescobri como profissional."

A escolha da carreira é um processo relacional que comporta para além da expectativa da venda da força de trabalho, percepções da relação entre a oferta e a procura de mão de obra que são determinadas em contextos econômicos, políticos e sociais. Tais determinações influenciam na orientação profissional na relação entre pais e filhos (DIAS; SOARES, 2007). A família para diversos autores (BARTALOTTI; MENEZES-FILHO, 2007; AMBIEL; NORONHA, 2011; RESENDE et al.,2011) é apontada como um dos principais elementos que podem tanto ajudar quanto dificultar para o jovem em sua escolha profissional . 
A escolha de uma profissão trata de ser uma ética em que a decisão está inter-relacionada com a sociedade e no caso da mulher também se relaciona com transpor obstáculos e construir o seu lugar no mundo do trabalho. Como nesta narrativa:

“- Trabalhar mais algum tempo como funcionária e depois ser empreendedora", "-Importante ser engenheira, mas sinto que podia ser mais e mais valorizada, inclusive financeiramente."

Com mais ênfase e clareza na atividade compensatória dos esforços a um bem último a ser alcançado, a escolha tornou-se uma apropriação de meios para se determinar em estratégias que se objetivam na acumulação. Conforme Laufer (2003, p. 133)

as mutações em curso relativas ‘a igualdade profissional ou às configurações que permitem a mulher articular o trabalho profissional e trabalho familiar e doméstico levam a uma transformação das noções de tempo e espaço que caracterizam a vida na cidade: novas fronteiras se desenham entre o tempo de trabalho e outros tempos sociais.

A escolha profissional das mulheres nas engenheiras também sofrem influência de histórias e trajetórias singulares, como nesta fala:

“- Por ter cursado o técnico em edificações."

Assim em um primeiro momento, termos uma assertiva na intersecção entre a fala e a busca de vantagens por um lado e por outro a continuidade de uma carreira potencialmente explícita já no segundo grau.

A ser considerado um problema para o ser humano, a escolha do trabalho hoje continua a ser a apropriação de conhecimentos sobre o mundo das profissões que se processam através das relações e interações humanas, nas instituições sociais. Escolher, portanto, uma profissão, é também relacionar motivos internos e subjetivos com influência de contextos de aprendizagem, como nestas falas:

\footnotetext{
“ - Tenho facilidade com raciocínio lógico, análises e matemática”,

“- Fiz ensino médio no CEFET e isto me guiou para a área técnica".
}

Independente das percepções de vantagens de escolher uma profissão talvez como uma mercadoria ou um fazer como uma ocupação somente, existem ideias e ideais, como nesta fala de uma egressa:

“- Escolhi engenharia para realizar um sonho".

A despeito das supostas aptidões, vocações, interesses econômicos, influências familiares e do mercado de trabalho, as mulheres escolhem a área tecnológica também por afinidades e por gosto.

Quanto adentram o mercado de trabalho as egressas expressam novas configurações subjetivas, que apontam para algo historicamente constituído, os obstáculos e os limites socialmente impostos na área. Como nesta fala de uma engenheira formada a seis anos na instituição:

“- A construção civil, no Brasil está absurdamente atrasada. O país é extremamente carente de infraestrutura de base, urbanização e moradia. 0 cenário do mercado de trabalho, na construção civil, mudou consideravelmente neste último ano, as vagas abertas foram encerradas, as vagas que estão sendo abertas exigem mais, o setor de projetos está quase 
parando, obras muito pouco. Os investidores estão saindo do país e buscando mercados mais seguros".

No enfrentamento desta cultura patriarcal um movimento se processa em suas falas:

“- Escolhi esta profissão pelo desafio".

Escolha profissional pode ser vista como múltiplas possibilidades de realização do humano, através do gosto por uma atividade, como nesta fala:

“- Sou uma pessoa perfeccionista e que gosta de cálculos, mas ao mesmo tempo tem interesse na engenharia de produção."

Uma escolha, acompanhando esse raciocínio, é sempre plural por suas múltiplas possibilidades de mediação, no entanto, entre a necessidade de sobrevivência, visibilidades e invisibilidades da mulher nas engenharias, participar de uma sociedade, corresponder às expectativas culturais, familiares e assumir o estrato histórico, existe um momento cultural da decisão que é ao mesmo tempo manifestação da vontade do singular enquanto seja sujeito social integrado à sua cultura.

\section{CONSIDERAÇÕES FINAIS}

O tempo de incrustação de um sistema educativo e de formação profissional determina a cristalização de uma cultura que o originou, que se diga que o perfil $\mathrm{da}(\mathrm{o})$ engenheira(o) possa reproduzir motivações descritas como afinidade com a área de exatas e gosto pelas engenharias ou aptidões para raciocínio lógico e matemático. A fala das mulheres apontam contradições em escolha motivadas pela continuidade de estudos na área técnica, pelas experiências e socializações em um campo das ciências exatas. Contradições também presentes nas expectativas do mercado de trabalho, e nas constatações obtidas a partir do ingresso neste mercado de trabalho. As remunerações percebidas pelas egressas promovem indiretamente uma busca por maiores qualificações, assim as escolhas iniciais parecem muitas vezes contradizer as trajetórias sócio profissionais em múltiplas direções para a gestão das empresas e para a carreira acadêmica.

Assim diplomas iguais não correspondem a iguais remunerações e as mulheres constatam a assimetria nos ambientes de trabalho. Se necessita reafirmar a necessidade das políticas de inserção social da mulher nos ambientes de trabalho e sua atuação profissional equivalente. As engenharias parecem possuir tal pragmatismo de uso e finalidade ferramental do ser humano, que toda a manifestação diferenciada pouco é aceita. É possível que a estrutura do ensino que se produz por pressão a resultados não alcance a totalidade dos alunos homens e mulheres, a não serem, portanto, percebidos como seres humanos singulares vivenciando as relações contraditórias entre formação e trabalho.

Equidade e justiça social, categorias que deram o início na contemporaneidade a grandes debates de políticas públicas, parecem não ter alcançado seu fundamento. Conforme a fala de uma egressa: 
"- O dito mercado de trabalho não se mostrou tão receptivo assim".

De fato a maioria das egressas, percebe o mercado como extremamente competitivo e muitas vezes excludente das mulheres.

As políticas públicas como estruturas diretivas para países em desenvolvimento, cristalizaram e determinam culturas de utilidade da formação superior focando em resultados. No entanto a construção do novo e de politicas socialmente mais avanças em termos de igualdade ultrapassam as limitações das relações de produção capitalistas. Assim o resultado destas politicas públicas igualitárias demonstram uma clivagem em relação às mulheres. Se marcaram as dinâmicas que reproduzem em diferenças entre as escolhas, onde os limites da formação e as barreiras do mercado de trabalho que visivelmente são impostos às mulheres como diferenciadores. Estas avançam em qualificações, em buscas por recursos para conciliar papéis sociais. Em ações e reações na defesa de seus direitos em profissões onde o masculino domina simbolicamente. Em geral políticas de inclusão social estão condicionadas ao utilitarismo, a mercantilização do trabalho. No qual egressas e egressos buscam alguma segurança, uma escolha que seja salvaguarda contra o desemprego. Com a coisificação da pessoa em uma cultura excludente da mulher ainda na contemporaneidade.

A questão de escolha profissional da mulher para áreas de engenharia denota as transformações socioculturais que se confirmaram com políticas públicas que ainda não satisfazem, pelas desigualdades salariais objetivadas nos perfis das egressas. A maior entrada da mulheres nas engenharias possibilitaram o emponderamento de outras mulheres, impactaram na tomada de suas decisões. Se as estratégias que as mulheres utilizam para o ingresso na carreira estão associadas à uma busca por maior qualificação profissional tal garantia não é busca de igualdade mas talvez ainda a afirmação de diferenças.

As motivações das escolhas do trabalho na área tecnológica se relacionam frequentemente com uma busca por maiores salários e condições de vida, no entanto em atividades supostamente equivalentes a mulher ainda recebe menor remuneração. A inserção na área está associada ao combate de diferentes formas de pressão e preconceitos vividos no ambiente universitário e que repercutem depois de formadas em um tipo de sofrimento ético e político vivido cotidianamente no trabalho. Apesar de os índices não serem de todo favoráveis, percebeu-se a mudança de perspectivas profissionais da mulher. Em superar os entraves do mercado de trabalho.

Apesar da aparente ascensão da mulher no mercado de trabalho em engenharias, a realidade em que vivem nos ambientes de trabalho mostram o contrário. Por mais que tenham a melhor formação, conhecimento e prática as mudanças em termos de carreira repercutem em sua subjetividade como um sofrimento de integração social, ético e político vivido no trabalho por ser mulher. Considera-se a partir da pesquisa que existe uma maior procura das mulheres por profissões nas áreas das engenharias e das tecnologias e que são necessárias outras pesquisas para aprofundar o debate sobre quem são as mulheres egressas do ensino superior brasileiro e o que buscam. 


\title{
The female choice in the area of technological professions impacts on subjectivity
}

\begin{abstract}
The social changes in work represent for women the mobilization of actions, configuring new ways of producing subjectivities. This article intended to address the female choice in the area of technological professions, analysed through part of a research that aimed to identify the profile of UTFPR of graduates in technology (engineering). As procedures, an online questionnaire was sent to (the) graduates (the) of engineering from 2005 to 2015. The results show $23 \%$ of women in engineering, they seek better wages and higher living standards through increased professional qualification. The insertion in engineering is associated with different combat form of prejudice and reverberate in a kind of ethical and political suffering at work. It concludes that the educational institutions should boost discussions on gender to face prejudice at work to privilege the right to diversity in the workplace.
\end{abstract}

KEYWORDS: Educational policies. Qualification. Professional choice. 


\section{REFERÊNCIAS}

AMBIEL, Rodolfo Augusto Matteo; NORONHA, Ana Paula Porto. Construção dos itens da escala de autoeficácia para escolha profissional. Psico-USF (Impr.), Itatiba, v. 16, n. 1, p. 23-32, Apr. 2011.

BARTALOTTI, Otávio; MENEZES-FILHO, Naércio. A relação entre o desempenho da carreira no mercado de trabalho e a escolha profissional dos jovens. Economia Aplicada, Ribeirão Preto, v. 11, n. 4, p. 487-505, Dec. 2007.

BOCK, Ana Mercês Bahia. A psicologia sócio-histórica: uma perspectiva crítica em psicologia. Em Furtado, O. (Orgs) A psicologia sócio-histórica: uma perspectiva crítica em psicologia.São Paulo: Cortez, 4ạ.Ed., p.15-35, 2002

CANTERA, Leonor Maria; CUBELLS, Maria Eugenia; MARTíNEZ, Luz Maria; BLANCH, Josep Maria. Work, family, and gender: elements for a theory of workfamily balance. The Spanish journal of psychology, v. 12, n. 2, p. 641-7, 2009.

DAUNE-RICHARD, Anne-Marie. Qualificações e representações sociais. In: MARUANI, Margaret; HIRATA, Helena (Org.). As novas fronteiras da desigualdade: homens e mulheres no mercado de trabalho. São Paulo: Senac, 2003. p. 65-76.

DIAS, Maria Sara De Lima; SOARES, Dulce Helena Penna. Jovem, mostre a sua cara: um estudo das possibilidades e limites da escolha profissional. Psicologia: Ciência e Profissão, v. 27, n. 2, p. 316-331, 2007. Conselho Federal de Psicologia. Disponível em: <http://www.scielo.br/scielo.php?script=sci_arttext\&pid=S1414-

DOWBOR, Ladislau. (2003) Prefácio à edição brasileira. Em MARUANI \& HIRATA (Orgs). As novas fronteiras da desigualdade : homens e mulheres no mercado de trabalho. Editora Senac, São Paulo, p11-14,2003.

FEDERAÇÃO NACIONAL DOS ENGENHEIROS- fne . Perfil ocupcional dos engenheiros no Brasil. Elaborado pelo DIEESE, 2016. Disponível em file:///C:/Users/user/Desktop/PerfilFNE_net.pdf. Acessado em: 12/02/2017.

GUIA DA CARREIRA, Disponível em : http://www.guiadacarreira.com.br/carreira/as-profissoes-mais-bempagas/Acessado em 15 de fevereiro de 2017. 
HIRATA, Helena; KERGOAT, Danièle. A divisão sexual do trabalho revisitada. Em Novas Configurações da Divisão Sexual do Trabalho. Em: MARUANI, Margaret \& HIRATA, Helena (Orgs). As novas fronteiras da desigualdade : homens e mulheres no mercado de trabalho. Editora Senac, São Paulo, 2003.

\section{INSTITUTO BRASILEIRO DE GEOGRAFIA E ESTATÍSTICA - IBGE. De Geografia E} Estatística - Ibge. 2014.

KÜHLKAMP, Clarine; TEIXEIRA, Enise Barth, SANDRIN, Letícia; MATTOS, Valéria De Bettio. Observatório da vida estudantil da universidade federal da fronteira sul: considerações acerca do perfil dos ingressantes na região oeste catarinense., Anais do V Seminário de Ensino Pesquisa e Extensão da UFFS, vol.5, 2015.

LOMBARDI, Maria Rosa. "Por que são tão poucas?": um estado da arte dos estudos em "Engenharia e gênero" / Coordenação Maria Rosa Lombardi.; Textos Fundação Carlos Chagas: Relatórios técnicos, V.49, 2016

MARUANI, Margaret \& HIRATA, Helena (Orgs). As novas fronteiras da desigualdade : homens e mulheres no mercado de trabalho. Editora Senac, São Paulo, 2003.

MONTERO, Maritza. Introducción a la Psicologia Comunitaria : desarrollo, conceptos y procesos. 1ạ. Edição, Buenos Aires, Paidós, 2005.

MONTERO, Maritza.Relaciones Entre Psicología Social Comunitaria , Psicología Crítica y Psicología de la Liberación : Una. Psykhe, v. 13, n. 2, p. 17-28, 2004b.

ORGANIZAÇÃO DAS NAÇÕES UNIDAS (ONU) 2016, Disponivel em http://www.onumulheres.org.br/onu-mulheres/sobre-a-onu-mulheres/ Acessado em 31 de março de 2017.

PLANALTO: http://www2.planalto.gov.br/acompanhe-o-planalto/cadernodestaques/marco-2012/mercado-de-trabalho

RESENDE, Tania de Freitas, NOGUEIRA, Cláudio Marques, \& NOGUEIRA, Maria Alice. (2011). Escolha do estabelecimento de ensino e perfis familiares: uma faceta a mais das desigualdades escolares. Educação \& Sociedade, 32(117), 953970. https://dx.doi.org/10.1590/S0101-73302011000400004

SARAIVA, Karla. Fabricando identidades femininas em Escolas de Engenharia. 
SCOTT, Joan. Gênero: Uma Categoria Útil Para Análise Histórica. Educação \& Realidade, p. 1-35, 1995.

TEIXEIRA, Adla Betsaida. Mulheres nas áreas Científicas e Tecnológicas Desinteresse ou preconceito? Modismo ou respeito aos direitos humanos? Instrumento - Revista de Estudo e Pesquisa em Educação, v. 12, n. 2, 2010.

Recebido: 01 de março de 2016.

Aprovado: 27 de março de 2016.

Como citar:

DIAS, Maria Sara de Lima. A escolha feminina na área das profissões tecnológicas: impactos na subjetividade. Cad. Gên. Tecnol., Curitiba, v. 9, n. 33, p. 3-21, jan./jun. 2016.

Correspondência:

Maria Sara de Lima Dias

Abilio Sebastiao da Silva, 49A, Abranches, Curitiba, Paraná, CEP 92130260

Direito autoral: Este artigo está licenciado sob os termos da Licença Creative Commons Atribuição 4.0 Internacional.

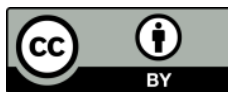

